\title{
How to Make a Maker Librarian
}

\author{
Heather Moorefield-Lang \\ University of North Carolina at Greensboro \\ Megan Coker \\ University of South Carolina
}

\begin{abstract}
Makerspaces are simply a location for open-exploration, tinkering, problem solving, and
critical thinking for all. This definition and idea ties in well to the focus of the Knowledge School.

Makerspaces and the librarians who work in them aim at being socially just, community based, and focus their maker learning locations toward their practitioners. Those in schools, universities, and communities who are often charged to implement a maker location. When a student graduates from a Masters of Library and Information Science program or iSchool are they are ready to work with makers in their community? Are they ready to learn and train themselves? Are they ready to continue growth in their own knowledge? Have their programs of study, their schools of knowledge trained them appropriately? This article delves into case studies focused on that very discussion.
\end{abstract}

Keywords: makerspaces, pre-service librarians, instruction

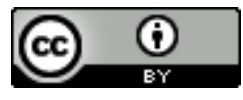

This is an Open Access article distributed under the terms of the Creative Commons Attribution 4.0 International License (http://creativecommons.org/licenses/by/4.0), which permits unrestricted use, distribution, and reproduction in any medium, provided the original work is properly cited.

Journal of New Librarianship, 4 (2019) pp. 371-379 10.21173/newlibs/7/9 


\section{Introduction}

How is a maker librarian trained, made, or created? The title of this article is simply a play on words. A school/department of library and information science doesn't make a librarian. They are a community of scholars. They are Knowledge Schools. They are iSchools. They come together as a collective, the students and instructors, to form a professional network in learning. In the field of librarianship, makerspaces or DIY locations in libraries have been growing in popularity in public, academic, and school libraries around the world. How do schools/department of library science ready pre-service librarians for these spaces? Some quickly ask in return, do we need to?

\section{Literature}

Oliver (2016a) begins by defining a makerspace as a unique and intentional opportunity for creative, self-directed learning which supports tinkering, allows for failure as part of the process, and encourages students to work together. Oliver stresses the importance of tailoring the makerspace to the needs of students, starting small and focusing on certain skill sets or activity types, and growing from there to best fit the population. Oliver advises developing the space and professional development by gauging skill sets through maker activities, collaborating with everyone involved, brainstorming, making things (from flowcharts to core value manifestos) as part of the process, and connecting with local and online maker communities.

According to Bevan et al. (2015), the concept of experimenting is central to makerspace activities for students and staff. By observing students tinkering with different scientific activities, the authors were able to identify the most essential elements of engagement, initiative and intentionality, social scaffolding (when learners support each other or work together), and the development of a new understanding. These attitudes and actions form a framework that educators can learn, teach, and use to facilitate learning and making. While different components were hard to spot at first glance, learning 
the framework and each part of the process allowed educators to more closely identify each element and its role in the process of making.

In the second article of his series, Oliver (2016b) addresses the question of how to maintain, outfit, and otherwise manage a makerspace, bringing in other aspects, which are all part of the making experience. The article is not a checklist or a cut and dry set of instructions but instead suggests crucial ideas to think through, such as including space for different steps in the learning and making process (demonstrating, collaborating, and working alone), planning supplies with an activity in mind, and offering different methods to sustain your space with a steady stream of new makers. Oliver also includes ideas for assessments and ways in which professional development and collaboration can be used to support the makerspace.

How does all of this apply specifically to librarians? According to Williams \& Folkman (2017), as libraries' communities and their information needs continue to shift and grow in different ways, fostering creative making and tinkering is an excellent way for library staff to meet those needs. As librarians' roles are reinvented along with library collections and spaces, new skills and strategies are necessary, from technical ability to flexibility, and other skills, which are not always included in LIS curricula. The authors focus on a case study intended to develop those competencies, involving a statewide program of library students and librarians as they created a collaborative community via webinars, presentations, and a conference for participants to test ideas and learn from each other. Their conclusion is clear: learning about the making process is a goal often reached through making and learning hands-on (Williams and Folkman, 2017).

This idea is seconded by the data and analysis of Moorefield-Lang (2015). Teacher librarians with makerspaces revealed that they most often learn how to use different tools and techniques through online resources; by consulting with peers, coworkers, family members, volunteers, or Journal of New Librarianship, 4(2019) pp. 371-379 10.21173/newlibs/7/9 
assistants; and, of course, through tinkering. As each new technology emerges, maker networks create and share tutorials and guides on using it. There is a learning curve involved in running a makerspace, but librarians are managing to navigate through it.

\section{Focus}

The focus of this study is on the training of pre-service librarians from the perspective of faculty and staff within schools/departments of library and information science. For this study, 12 participants were interviewed. The interviewees consisted of nine faculty members from schools of library and information science, iSchools, and academic libraries. The remaining three participants were a learning consultant, graduate student, and director of a teaching resource center. Those interviewed taught either in their school/department's makerspace or had formed a partnership between their school/department and a local makerspace. The goal was to find out how maker learning areas were being used in or with schools and departments of library and information science (iSchools, Knowledge Schools).

Some questions asked included:

1. Where is your maker learning space housed? In your department? Part of the school or department? Elsewhere?

2. Do you share your makerspace with other departments or schools? If so whom?

3. Why did you decide to take the step to implement the makerspace?

4. How is the makerspace being used at this time? (Ex: Professor training, student experimentation, professional development, classes)

5. Is the makerspace integrated into course curriculum with the School/Department of Librarianship? 
6. How is the makerspace being used with students at a distance? Might you provide examples, classes, projects?

7. What training was provided to you or to your staff before working with the makerspace?

8. What has been the overall reaction to your makerspace?

9. What have been the challenges of implementing this service?

Follow-up questions were asked as needed during the interview process. Commonalities between the twelve interviews were few. As with makerspaces in library settings, no two makerspaces in a school or department of library and information science were the same. Each faculty member had their own audience, technology, lens, and plan for implementation for their maker learning location. Common themes that emerged during the interviews were implementation, curriculum, and partnerships. These will be the focus of conversation for this article.

\section{Conversations}

\section{Implementation}

During the designing process, the best ideas are prototyped or put into a concrete action. These ideas are put into play. In other words, they are implemented (Brown \& Wyatt, 2010). When seeking to implement making or makerspaces into the curricula of a school of library and information science, faculty and staff must look to their community. Who are the students? What community are they serving? What technology or space should be provided? Is this an individual space or does it move? How does this space for making or a makerspace partnership fit into the overall plan for the school or department? How will this space be implemented and is there an action plan? Matt Ratto and Jess Whyte were both located at the iSchool @Toronto within the University of Toronto at the writing of this research piece. Matt is an Associate Professor in the Faculty of Information at the 
University of Toronto and directs the Semaphore Research cluster on Inclusive Design, Mobile and Pervasive Computing and, as part of Semaphore, the Critical Making lab. The critical making lab is housed in the Faculty of Information and is there for classes, doctoral student experimentation, and faculty collaborations.

Jess Whyte was a graduate student in the same program and was tasked for her graduate research with the creation of Studio 307. (She has since gone on to graduate from the program) This location was created for students, workshops, collaborations, and career-driven projects. In other words, this iSchool had a maker location for research mainly at the doctorate and faculty level and they realized their community also needed a space for the school at large and opened Studio 307. Jess explains further:

The idea is to create this space, Studio 307 - it's room 307 - which will have that kind of basic equipment accessible 24 hours to the students, and then also run workshops that are both career focused ... Say you're interested in being a public librarian and you want to take a workshop on basic troubleshooting and maintenance of a 3D printer. That's an option, but then there will also be multi-session more theoretical workshops.

We might do a series of workshops on internet of things and personal privacy. You would learn how to create an internet of thing, with an arduino object, but then you would also ... a component of that would be talking with the theory behind that. Personal privacy implications, or something on wearables and the body, and extending the body. Some of it will be more theory, and some of it will be what we call 'I skills', so career focused workshops. For example, for the museum students, a workshop on how to set up an exhibit using a pie. There will be two dimensions, but it's intended to be accessible to the graduate students.

The Critical Making Lab was established, had been for a decade, its purpose was clear for the students and faculty it served. Through her research as well as her practice, Jess implemented a maker location for the remaining needs of the community within the iSchool @Toronto.

\section{Curriculum}

For this research piece, participants were asked a variety of questions on how the maker learning spaces was being used with students and faculty, within the curriculum, professional 
development, and in professor training. How a makerspace could be used within a distance or online library science program was also of great interest.

It was quickly determined while analyzing the data, that while the maker learning spaces at each institution were being used with school curriculum in mind, there was very little in the way of commonality. As stated earlier, each makerspace was different, each location served a different population and clientele, and it would make sense that different classes and professors would use a makerspace located in or collaborated with a school of library science. Anthony Molero from St. Katherines in St. Paul, MN discussed how the makerspace had a longevity past the end of the semester. He said, "So mostly it's for my course and student projects and the interesting thing as a faculty member... When students are typically done with my class, it's like 'See ya later.' For making, they come back. And they use equipment, they borrow equipment, they go and present using my equipment."

Maker learning spaces can be used to enhance a variety of courses in an iSchool or Knowledge School. Some examples might include: instructional media, library technology systems, innovative or emerging technologies, computer literacy, and introduction to educational technology.

Professional development was also very popular. Interviewees used the makerspace to train graduate students, faculty, teachers, and librarians in public libraries and public schools across their particular states. Training and development were popular areas for outreach and service. Kristin Fontichiaro with the University of Michigan has a partnership with the Ann Arbor District Public Library's Secret Lab and described their mobile professional development efforts:

We have a project that's funded by the Institute for Museum and Library Services called the Making in Michigan Libraries trip. We're working in 11 cities this summer to do professional development with then some follow-up work, in depth work with a couple of libraries over the course of three years. We have already started some shorter events and then we're going to do some three-day events. We're really looking at the communities beyond Detroit, Lansing, Ann 
Arbor, Grand Rapids. Those are places that have a lot of maker stuff and entrepreneurial stuff and we're trying to take what does that look like when we move it into communities that are three hours away from those spots. For me, that has been really valuable because we're really thinking about how are we culturally responsive to those communities.

\section{Partnerships}

While seeking interviewees and following recommendations for new participants, it became increasingly clear throughout this process that few iSchools, Knowledge Schools, and schools of library and information science had their own maker learning spaces. There were some but not many. Partnerships were the order of the day. In some instances, a school was part of a larger department. For example, Lori Sands is the Director of the Teaching Resource Center at the University of North Carolina at Greensboro. The Department of Library and Information Studies is housed within the School of Education. Their SELF (Student Educator Learning Factory) Design Studio is part of the School and the Teaching Resource Center and available for all departments. Lori described it this way, when I asked her about partnerships outside of the School of Education:

We don't share ownership of it. It is not tied to the LIS Department; it is a part of the entire School of Ed. We have six departments, but as far as other schools on campus, we don't share ownership, but we do offer it as a space that they're welcome to use and collaborate with us. We have had some people in other departments on campus who have used the space. I would like to do more of that.

Partnerships within the school can be quite common; others have to go outside of the school to find their maker partnerships. An example would be Rebekah Willett with the University of Wisconsin. Her partnership includes the Information School at the University of Wisconsin-Madison and the Bubbler Maker Program at the Madison Public Library. The Bubbler program is much more than just a maker learning space; it is a full community program. When asked to describe it Rebekah said:

Madison Public Library has nine libraries. The neighborhood libraries are often in strip malls, so they are really embedded in the community. Then there's a central library, which is right near 
the capitol building. It is right in the downtown area of Madison I guess you would call it. That has a dedicated maker space called the Bubbler room, which is a messy room. That has an artist in residence program.

The artists, and that changes every month or two months, depending. That artist is there. They commit a number of hours to that space, and they also set up passive programming in that space. There's always something for people to be doing, either a drop-in programming and they can take their craft, or some sort of passive programming going on in that space.....

Madison Bubbler works with court involved teens, shelters, neighborhood intervention

programs, and so much more. Rebekah and her students at the Information School at the University of Wisconsin-Madison have partnerships, internships, practica, and classes with the Bubbler. A partnership that has far-reaching effects for the school and community. Opportunities for co-creation make for strong partnerships and collaborations (Boyle et al., 2016). The schools of library and information science, iSchools, and Knowledge Schools in this research piece are seeking ways to engage and graduate a more well-rounded student suited for today's libraries and for the libraries serving future communities.

\section{Conclusion}

Knowledge Schools and other schools of library science are graduating students who will be employed in an ever-changing field. The specifics of training a pre-service librarian or information scientist on the basics of making, creating, or hacking is not truly where the focus should lie. Currently few schools of library science have their own maker locations, and libraries are in a constant state of flux. The question to ask is, what services will be offered in ten years? What about soft skills, including problem solving, collaboration, critical thinking, advocacy, and knowledge of technologies? Students should have these skills when departing from schools of library and information science. The ability to move with the future, train, and solve a problem when it occurs; this is the training needed in iSchools and Knowledge Schools. 


\section{References}

Bevan, B., Gutwill, J. P., Petrich, M., \& Wilkinson, K. (2015). Learning through STEM-rich tinkering: Findings from a jointly negotiated research project taken up in practice. Science Education, 99(1), 98-120.

Boyle, E., Collins, M., Kinsey, R., Noonan, C., \& Pocock, A. (2016). Making the case for creative spaces in Australian libraries. The Australian Library Journal, 65(1), 30-40.

Brown, T., \& Wyatt, J. (2010). Design thinking for social innovation IDEO. Development Outreach, 12(1), $29-31$.

Fleming, Laura. (2015). Worlds of making. Best practices for establishing a makerspace for your school. Corwin Press.

Moorefield-Lang, H. (2015). Change in the making: Makerspaces and the ever-changing landscape of libraries. TechTrends, 59(3), 107.

Oliver, K. M. (2016a). Professional development considerations for makerspace leaders, part one: Addressing "what?" and "why?". TechTrends, 60(2), 160-166.

Oliver, K. M. (2016b). Professional development considerations for makerspace leaders, part two: Addressing "how?". TechTrends, 60(3), 211-217.

Williams, B., \& Folkman, M. (2017). Librarians as makers. Journal of Library Administration, 57(1), 17-35. 